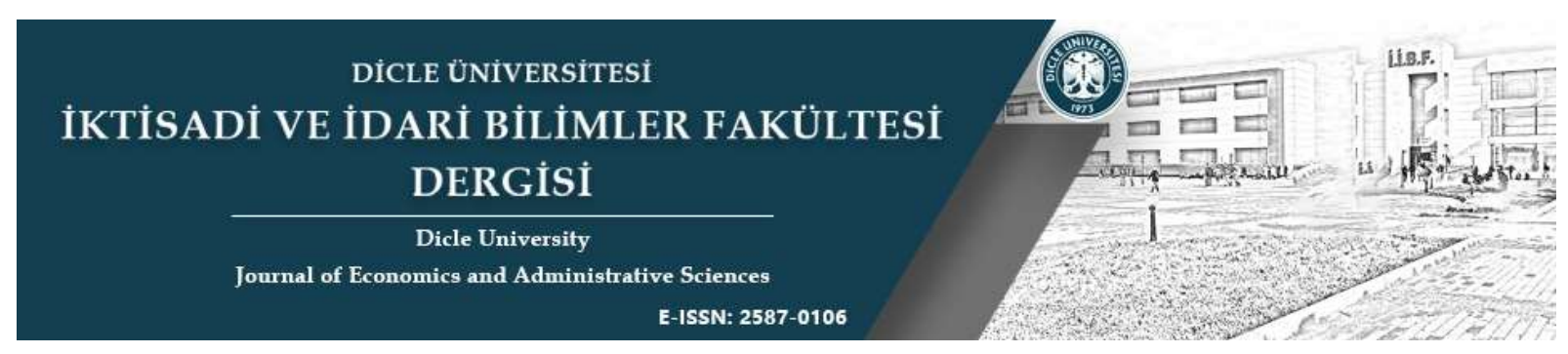

Cilt / Volume: 11, Sayı / Issue: 22, Sayfalar / Pages: 295-315

Araştırma Makalesi / Research Article

Received / Alınma: 13.07.2021

Accepted / Kabul: 22.08.2021

\title{
FORECASTING BITCOIN PRICES WITH THE ANFIS MODEL
}

\author{
Büşra KUTLU KARABIYIK ${ }^{1}$ \\ Zeliha CAN ERGÜN ${ }^{2}$
}

\begin{abstract}
Recently, Bitcoin has gained great importance in the cryptocurrency market with the highest market capitalization. Investors and researchers have attempted to find out the drivers of Bitcoin prices and if they are predictable. However, there is only limited research in the literature that identifies the most effective economic and technical variables for predicting Bitcoin prices using machine learning models. Thus, in this study, the future Bitcoin prices utilizing several economic and technical factors using the ANFIS model are aimed to forecasted between 01.05.2013 - 26.02.2021 periods. The findings show that the ANFIS model produced accurate and consistent predicting results that are in line with the real data. As a result, investors who wish to make a profit by predicting future Bitcoin values might consider using the ANFIS approach as a forecasting tool.
\end{abstract}

Keywords: Cryptocurrency, Bitcoin, Forecasting, Machine Learning, ANFIS.

Jel Codes: C45, F37, G15, G17.

${ }^{1}$ Dr. Arş. Gör., Aydın Adnan Menderes Üniversitesi, e-posta: busra.kutlu@adu.edu.tr, ORCID: 0000-00026691-2921.

${ }^{2}$ Dr. Arş. Gör., Aydın Adnan Menderes Üniversitesi, e-posta: zeliha.can@adu.edu.tr, ORCID: 0000-0003-33579859.

\section{Atıf/Citation}

Kutlu Karabıyı,, B., \& Can Ergün, Z. (2021). Forecasting Bitcoin Prices with the ANFIS Model. Dicle Üniversitesi Iktisadi ve İdari Bilimler Fakültesi Dergisi, 11(22), 295-315. 


\section{ANFIS MODELİ İLE BITCOIN FIYYAT TAHMINI}

\section{$\ddot{O} z$}

Son zamanlarda piyasa değeri en yükseğe ulaşan Bitcoin, kripto para piyasasında büyük önem kazanmıştır. Bu yüzden, yatırımcılar ve araştırmacılar, Bitcoin fiyatlarını etkileyen faktörleri ve bunların tahmin edilebilir olup olmadığını bulmaya yönelik çalışmalar yürütmektedirler. Fakat literatürde, makine öğrenimi modellerini kullanarak Bitcoin fiyatlarını tahmin etmek için en etkili ekonomik ve teknik değişkenleri tanımlayan sınırlı sayıda araştırma bulunmaktadır. Bu nedenle bu çalışmada, çeşitli ekonomik ve teknik faktörler kullanılarak Bitcoin fiyatlarının ANFIS modeli ile 01.05.2013-26.02.2021 tarihleri arasında tahmin edilmesi amaçlanmaktadır. Bulgular, ANFIS modelinin gerçek verilerle uyumlu, doğru ve tutarlı tahmin sonuçları ürettiğini göstermektedir. Sonuç olarak, gelecekteki Bitcoin değerlerini tahmin ederek kar elde etmek isteyen yatırımcılar, bir tahmin aracı olarak ANFIS yaklaşımını tercih edebilirler.

Anahtar Kelimeler: Kripto para, Bitcoin, Tahminleme, Makine Öğrenimi, ANFIS.

Jel Kodlari: C45, F37, G15, G17.

\section{INTRODUCTION}

Technological advancements, the internet era, and Industrial 4.0 have generated a demand for rapid and reliable financial transaction systems. In this regard, cryptocurrencies (digital currencies) have recently acquired popularity. Cryptocurrency's estimated market capitalization has already exceeded the hundreds of billions of dollars threshold. Furthermore, according to the Fortune Business Insight report (2020), the global cryptocurrency market size was $\$ 754.0$ million in 2019 but is predicted to grow to $\$ 1,785.0$ million by 2027 . The most important distinction between cryptocurrencies and fiat currencies is that they are not created by governments and do not obey any country's laws. Because of its inexpensive transaction costs, peer-to-peer system, and government-free nature, cryptocurrencies have attracted a lot of media and investment attention (Shen et al., 2019).

Today, Bitcoin is the most popular cryptocurrency with a market capitalization of $\$ 659$ billion (coinmarketcap.com). It was created in 2009 by an anonymous person or group known only as Satoshi Nakamoto. It is digital money that is produced through a mining process, traded over the internet, and tracked by a decentralized ledger called the blockchain. According to Satoshi Nakamoto's original paper, Bitcoin allows two parties to interact without the involvement of a third party (Nakamoto, 2009). As a result, Bitcoin transactions are anonymous, low-cost, and quick (Chen et al., 2021). Bitcoin values have risen dramatically in recent years, making them more appealing to investors. Edwards (2021) reported that the initial price increase of Bitcoin occurred in 2010 by climbing from roughly $\$ 0.0008$ to $\$ 0.08$. After that year, various rallies and collapses have influenced its pricing. Specifically, during the Covid-19 outbreak, government shutdowns and policies made investors fearful of the 
global economy, prompting them to invest in the Bitcoin market (Edwards, 2021). Bitcoin's closing price at the start of 2020 was $\$ 7,200$, and at the end of the year, it had risen to around $\$ 32,127.0$. Notably, the closing price of Bitcoin reached a peak of $\$ 61,243.086$ in March 2021 (coinmarketcap.com).

Such sharp increases cannot be explained solely by the standard economic or financial theories, and thus Kristoufek (2013) emphasized that the short-term investors, trend chasers, noise traders, and speculators are the main dominators of the cryptocurrency market. In addition to being a means of exchanging money, Bitcoin has recently considered as leading investment opportunity, arousing the curiosity of many researchers and investors (Jay et al., 2020). Bitcoin prices are impacted by several factors, including sentiments, financial markets, regulatory obstacles, and market trends, all of which influence their volatility and instability (Patel et al., 2020). Investors and researchers have spent a lot of time attempting to figure out what drives Bitcoin prices and whether or not they are predictable.

Most of the studies used traditional econometric models (such as VAR, VECM, and GARCH) to find the determinants of Bitcoin prices (i.e., Georgoula et al., 2015; Kristoufek, 2015; Malik, 2020). However, due to their limitations in capturing nonlinear dynamics, traditional econometric models are seen to be inadequate in forecasting cryptocurrencies. (Altan et al., 2019; Pintelas et al., 2020; Patel et al., 2020). Since the Bitcoin prices generally have nonlinear, erratic, and volatile patterns, many other studies used machine learning algorithms (such as LSTM, CNN, and ANN) to capture the nonlinear dynamics and to predict the Bitcoin prices (i.e., Altan et al., 2019; Ji et al., 2019; Liu et al., 2021). Without depending on conventional hypotheses, machine learning algorithms can capture nonlinear relationships, resulting in more reliable Bitcoin forecasting results (Altan et al., 2019; Pintelas et al., 2020).

Yet, there is a limited research in the literature that determines the most effective economic and technical factors for predicting Bitcoin prices using machine learning models (i.e., Chen et al., 2021). As a result, in this study, it is aimed to forecast the future Bitcoin prices by using several economic and technical variables with the help of the neural network's method (ANFIS).

Jang (1993) introduced the ANFIS model, which is one of the neural fuzzy techniques that combines neural network learning ability with fuzzy logic models' capacity to ensure decision making like individuals and provide expert knowledge. As emphasized by Bayramoğlu et al. (2017) the ANFIS approach is one of the intelligence strategies that may generate extremely 
good outcomes for prediction issues. The closing prices of the Bitcoin cryptocurrency are forecasted using economic (i.e., S\&P 500 index, Dow Jones index, gold price, crude oil price and EUR/USD, CNY/USD, and JPY/USD exchange rates) and technical variables (i.e., hash rate, mining difficulty, miner's revenue, number of transactions, average block size, Bitcoins in circulation, cost per transaction and the total number of unique addresses). The period covered by the data is from May 1, 2013, to February 26, 2021.

The rest of the paper is as follows: The second section critically reviews the literature. The third section explains the details of the ANFIS framework. The fourth section presents the data. The fifth section documents the empirical results. The last section concludes the paper.

\section{LITERATURE REVIEW}

Many studies examined the determinants of Bitcoin prices by using either econometric or machine learning methods. In the literature section, first, the studies that focus on the determinants of Bitcoin prices will be explained, and second, the studies that used machine learning models to predict Bitcoin prices will be summarized.

To figure out the potential drivers of Bitcoin prices, Kristoufek (2015) applied wavelet analysis. The first finding indicates that the fundamental factors (i.e., usage in trade, money supply, and price level) are observed to influence the Bitcoin prices in the long term. The second finding shows that the technical indicators (i.e., difficulty and hash rate) are positively correlated with the prices. The last finding demonstrates that investors' interest is also a main driver of the Bitcoin prices. Furthermore, Ciaian et al. (2016) used the VAR model to investigate the price drivers of Bitcoin. As a consequence, they found that supply and demand market factors, as well as investor speculative behavior, have a considerable influence on Bitcoin prices. The findings, however, suggest that macro-financial developments have no long-term impact on Bitcoin prices. Moreover, Georgoula et al. (2015) examined the effects of fundamental economic factors, technological factors, and Twitter sentiment on Bitcoin prices. The results show that in the short term while the Twitter sentiment ratio, Wikipedia search queries, and the hash rate are positively related to the Bitcoin prices, the USD/Euro exchange rate is inversely related. To detect the long-term relationship VECM approach is used, and the number of Bitcoins in circulation is found to be positively related, whereas the S\&P 500 index is found to be inversely related to Bitcoin prices. Malik (2020) also used the VECM approach to investigate the determinants of Bitcoin prices in India. The findings 
demonstrate that, while Bitcoin supply, gold prices, money supply, and Bitcoin trade volume are significant predictors of Bitcoin prices, Google trends and inflation have no impact.

Guizani \& Nafti (2019), Li \& Wang (2017) and Sovbetov (2018) used the ARDL model to examine the determinants of Bitcoin prices. Li \& Wang (2017) investigated both technical (i.e., mining difficulty and public recognition) and economic (i.e., USD money supply, US GDP, US federal fund interest rates, US inflation rates, Bitcoin supply, transaction value and transaction volume, trading volume, and volatility) factors. They found that economic variables have a short-term impact on Bitcoin prices. However, particularly after Mt. Gox closed, economic variables become more effective, and the technical factors become less effective in the long term. Furthermore, while mining technology has a substantial impact on Bitcoin pricing, the importance of mining difficulty has been reduced. The number of addresses, investor attractiveness, and mining difficulty, on the other hand, are determined to be major predictors of Bitcoin pricing by Guizani \& Nafti (2019). However, transaction volume, stock exchange, EUR/USD exchange rate, and macroeconomic and financial events have no influence. In addition to Bitcoin, Sovbetov (2018) also examined the determinants of Ethereum, Dash, Litecoin, and Monero. Both in the short- and long-term cryptocurrency market-related factors (i.e., market beta, trading volume, and volatility) are the significant determinants for all analyzed cryptocurrencies, but the attractiveness is significant only in the long-term. On the other hand, the impact of the S\&P 500 index on Bitcoin, Ethereum, and Litecoin is weak and positive in the long term, while in the short term the impact becomes negative and weaker.

Moreover, Panagiotidis et al. (2018) examined the significance of twenty-one probable Bitcoin return drivers with a LASSO approach. The most significant variables observed to determine Bitcoin returns are Google search intensity, gold returns, and policy uncertainty. Poyser (2019) used the Bayesian structural time series (BSTS) methodology to investigate the relationship between internal and external variables and Bitcoin prices. According to the findings, gold prices and the CNY/USD exchange rate are adversely related to Bitcoin prices, whereas the stock market index and the USD/Euro exchange rate are positively related to Bitcoin prices.

Furthermore, Adjei (2019) applied the GARCH-M approach to analyze the association between Bitcoin mining technology factors and Bitcoin returns. According to the findings, mining difficulty and block size have an inverse relationship with Bitcoin returns, and these technical variables are also a predictor of future returns. Chen et al. (2021) examined the 
determinants by implementing the GARCH model and found that while the exchange rates, the DAX and the Nikkei 225 are positively related to the Bitcoin prices, Fed funds rate, the FTSE 100, and the USD index are negatively related. Particularly, the significance levels of the Fed funds rate, the Euro/GBP rate, the USD/GBP rate, and the West Texas Intermediate price are higher compared to the other variables. They also suggested that the machine learning approaches are more suitable to predict the Bitcoin prices after implementing decision tree and support vector machine (SVM) methods.

Since cryptocurrencies have a nonlinear structure, many studies preferred to use various machine learning models to forecast Bitcoin prices. In general, researchers compared the efficacy of several machine learning techniques and other models in forecasting cryptocurrency values. For instance, Ji et al. (2019), Lahmiri \& Bekiros (2019) and Mudassir et al. (2020) evaluated multiple models and concluded that the Long Short-Term Memory (LSTM) model performs better in forecasting cryptocurrency prices. Pintelas et al. (2020), on the other hand, contrasted LSTM to Bidirectional Long Short-Term Memory (BLSTM) and Convolutional Neural Networks (CNN) and concluded that none of the models are efficient. Furthermore, Altan et al. (2019) and Li \& Dai (2020) employed hybrid models based on LSTM and empirical wavelet transform (EWT) approaches, as well as LSTM and convolutional neural networks $(\mathrm{CNN})$. Both studies reported that a hybrid model is more successful than a single model for anticipating values. In addition, Lamothe-Fernández et al. (2020) argued that the deep recurrent convolutional neural network (DRCNN) model performed well in predicting the prices of Bitcoin.

Furthermore, McNally et al. (2018) employed Recurrent Neural Network (RNN) and LSTM algorithms to forecast Bitcoin values, and they discovered that these methods outperformed the traditional time series model (i.e., ARIMA). Struga \& Qirici (2018) also employed the LSTM version of RNN and found that deep neural networks are successful at prediction. According to Jaquart et al. (2021) RNN and gradient boosting classifiers outperformed other machine learning models. However, Albariqi \& Winarko (2020) compared RNN to the Multilayer Perceptron (MLP) model and discovered that MLP outperforms RNN. Moreover, Aggarwal et al. (2020), Akyildirim et al. (2021), Karasu et al. (2018) and Poongodi et al. (2020) used a Support Vector Machine (SVM) learning technique and found that the SVM model performs better. On the other hand, Liu et al. (2021) compared the Stacked Denoising Autoencoders (SDAE) method to Back Propagation Neural Network (BPNN) and SVM, and SDAE is reported to perform better than BPNN and SVM. 
Another popular machine learning technique is the Artificial Neural Networks (ANN) model. ANN is employed by Nakano et al. (2018) to evaluate Bitcoin trading performance, and they discovered that this method improves Bitcoin's performance, especially during periods of negative trends. ANN also is proven to be an effective model in predicting future Bitcoin values by Yavuz et al. (2020). To anticipate Bitcoin price volatility, Kristjanpoller \& Minutolo (2018) constructed a hybrid model based on ANN and Generalized Autoregressive Conditional Heteroscedasticity (GARCH). Similarly, Jay et al. (2020) proposed a stochastic neural network model for Bitcoin, Ethereum, and Litecoin price prediction, which has been proven to be highly efficient in predicting. On the other hand, Atsalakis et al. (2019) proposed PATSOS, a neuro-fuzzy paradigm for forecasting Bitcoin prices, and after comparing the PATSOS model to an ANN and a hybrid ANFIS model, the suggested model is found to be more successful. Sin \& Wang (2017) employed a Genetic based Selective Neural Network Ensemble (GASEN) ANN ensemble technique, which was found to perform effectively.

One of the other techniques that are used by the researchers is the Bayesian neural networks (BNN) model. BNN works well in forecasting Bitcoin values, according to Jang \& Lee (2017). Furthermore, Dutta et al. (2020) implemented the gated recurring unit (GRU) model, which outperformed other popular models. Loh \& Ismail (2020) also examined three neural networks: the Feedforward Neural Network (FNN), the Nonlinear Autoregressive with Exogenous Input (NARX) Neural Network, and the Nonlinear Autoregressive (NAR) Neural Network. The results showed that NARX outperformed FNN and NAR, indicating that it is more appropriate to predict Bitcoin values. In another study, Loh et al. (2020) examined two backpropagation algorithms: the Levenberg-Marquardt (LM) method and the Scaled Conjugate Gradient (SCG) method utilizing FNN. It is found that, in forecasting Bitcoin values, LM outperforms SCG when utilizing FNN.

Different from previous studies, Chen et al. (2021) conducted one of these studies to investigate the accuracy of economic and technological determinant prediction capabilities. First, they employed Artificial Neural Networks (ANN) and random forest (RF) techniques to determine how various economic and technological variables impact Bitcoin values over time and found that they are effective determinants. Second, they employed the Long Short-Term Memory (LSTM) methodology and confirm that economic and technological variables may accurately anticipate the Bitcoin values.

In sum, multiple econometric models show that several economic (i.e., gold price, crude oil price, and exchange rates) and technical factors (i.e., hash rate, and mining difficulty) are 
effective in determining Bitcoin values. However, because of the nonlinear dynamics of Bitcoin prices, econometric models are sometimes insufficient to forecast them, and many other researchers have used machine learning methods instead. However, it is observed that there is limited research in the literature that determines the most efficient economic and technical variables for predicting Bitcoin values by using machine learning models. As a result, our research aims to anticipate future Bitcoin values utilizing several economic and technical variables and the neural networks approach (ANFIS).

\section{ADAPTIVE NEURO-FUZZY INFERENCE SYSTEM (ANFIS) METHOD}

The Adaptive Neuro-Fuzzy Inference System (ANFIS) model which is proposed by Jang (1993) is one of the neural fuzzy approaches that combine the learning ability of neural networks and fuzzy logic models' ability to ensure decision making like humans and providing expert knowledge. ANFIS method is known as one of the intelligence techniques that can produce very successful results for prediction problems (Bayramoğlu et al., 2017).

ANFIS model is based on the determination of the appropriate fuzzy rule set using a specific input-output data set and the systematic adjustment of system parameters through an adaptive network structure. In the figure below, a first order Sugeno-type ANFIS structure that has two inputs are pointed out.

Figure 1. ANFIS Structure

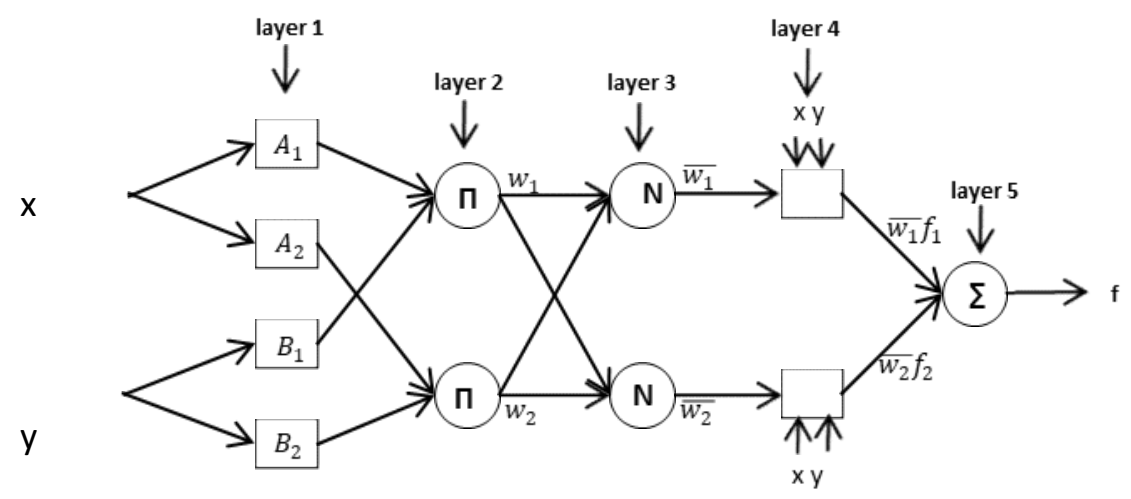

Source: Jang, 1993.

The ANFIS model has five layers of architecture. All layers are indicated below in detail (Urfalığlu \& Tanrıverdi, 2018; Yücel \& Güneri, 2010).

Layer 1: It is the fuzzification layer. The outputs of this layer are fuzzy membership degrees of inputs. The membership function gives the degree of how much $\mathrm{x}$ meets A. 


$$
\mathrm{o}_{\mathrm{i}}^{1}=\mu_{\mathrm{A}_{\mathrm{i}}}(\mathrm{x})
$$

Layer 2: It is the rule layer. In this layer, each circle-shaped node (П) multiplies the incoming signals and subtracts the value. Each node output shows the firing strength of each rule.

$o_{i}^{2}=w_{i}=\mu_{A_{i}}(x) \times \mu_{B_{i}}(x), i=1,2$

Layer 3: It is the normalization $(\mathrm{N})$ layer. The outputs of this layer are qualified as normalized firing strength.

$$
o_{i}^{3}=\overline{w_{l}}=\frac{w_{i}}{w_{1}+w_{2}}, i=1,2
$$

Layer 4: It is the defuzzification layer. While $\overline{\mathrm{w}_{1}}$ is an output of the Layer $3,\left\{\mathrm{p}_{\mathrm{i}}, \mathrm{q}_{\mathrm{i}}, \mathrm{r}_{\mathrm{i}}\right\}$ are qualified as parameters.

$$
o_{i}^{4}=\bar{w}_{l} f_{i}=\bar{w}_{l}\left(p_{i} x+q_{i} y+r_{i}\right), i=1,2
$$

Layer 5: It is the summation layer. The single node in this layer $\left(\sum\right)$ calculates an output by summing all incoming signals.

$$
o_{i}^{5}=\sum_{i} \bar{w}_{l} f_{i}=\frac{\sum_{i} w_{i} f_{i}}{\sum_{i} w_{i}}, i=1,2
$$

Figure 2. Phases of Forecasting with ANFIS Method

1) Input and output variables are determined.

2) All variables are normalized.

\section{Designing Dataset}

\begin{tabular}{|l|}
\hline \multicolumn{2}{|c|}{ Selection of ANFIS Input Variables } \\
\hline 3) Dataset is split into two subsets as train and test data. \\
\hline 4) With the ANFIS input selection method, the inputs that have the most impact on the output are determined. \\
\hline Creating ANFIS Model and Future Forecasting \\
system, the error tolerance of the training, the optimization method, and the number of cycles are determined. \\
\hline 6) Forecast is made for test data with ANFIS GUI interface of MATLAB fuzzy logic module. \\
\hline
\end{tabular}

\section{DATA DESCRIPTIONS}

In this paper, economic and technical variables are utilized for forecasting the Bitcoin cryptocurrency's closing prices. Economic variables are stated as S\&P 500 index, Dow Jones index, gold price, crude oil price and EUR/USD, CNY/USD, and JPY/USD exchange rates. Bitcoins' technical variables are also addressed as hash rate, mining difficulty, miner's revenue, number of transactions, average block size, Bitcoins in circulation, cost per 
transaction, and the total number of unique addresses. It is important to note that all of the variables which are discussed are highly preferred and accepted variables in the field literature (i.e., Bitcoin price forecasting). In the next lines, the variables' definitions will be discussed briefly. Besides, in the table below (Table 1) all obtained variables, their resources, and references will be summed up.

Economic variables can be represented, respectively. The Standard and Poor's 500 index (S\&P 500 index) consists of the stocks of the 500 highest value companies operating in the United States (US). Dow Jones index is a well-known stock market index that tracks the stock market performance of 30 major US companies. Gold and crude oil prices obviously demonstrate the price of these instruments. Finally, EUR/USD, CNY/USD, and JPY/USD concepts indicate the exchange rates between major fiat currencies as Euro/USD, Chinese Yuan/USD, and Japanese Yen/USD.

Bitcoins' technical variables can be described, respectively. Hash rate implies the estimated number of Tera hashes per second by all miners on the Bitcoin network. Mining difficulty indicates the difficulty of mining blockchain blocks. Miner's revenue concept indicates the total value of coin-base block rewards and transaction fees paid to miners. The number of transactions refers to the total number of confirmed transactions per day. Average block size points out to the size of the data in the blockchain which is verified by all participants. Bitcoins in circulation notion indicates the total amount of mined Bitcoins in circulation. Cost per transaction implies miners' income that is divided by the number of transactions. Lastly, the Total number of unique addresses refers to the total number of unique Bitcoin addresses used in a day.

Table 1. Variables, Data Resources and References

\begin{tabular}{|c|c|c|}
\hline Output & Resources & Utilized references that are used to forecast Bitcoin prices \\
\hline Bitcoin Prices & https://tr.investing.com & - \\
\hline \multicolumn{3}{|l|}{ Inputs } \\
\hline & & Economical Variables \\
\hline S\&P 500 index & https://tr.investing.com & $\begin{array}{l}\text { (Chen et al., 2021; Dutta et al., 2020; Jang \& Lee, 2017; Jaquart } \\
\text { et al., 2021; Li \& Dai, 2020; Liu et al., 2020; Mallqui \& } \\
\text { Fernandes, 2019; Struga \& Qirici, 2018) }\end{array}$ \\
\hline $\begin{array}{l}\text { Dow Jones } \\
\quad \text { index }\end{array}$ & https://tr.investing.com & $\begin{array}{l}\text { (Jang \& Lee, 2017; Lamothe-Fernández et al., 2020; Liu et al., } \\
\text { 2020; Struga \& Qirici, 2018) }\end{array}$ \\
\hline Gold price & https://tr.investing.com & $\begin{array}{l}\text { (Chen et al., 2021; Dutta et al., 2020; Jang \& Lee, 2017; Jaquart } \\
\text { et al., 2021; Lamothe-Fernández et al., 2020; Li \& Dai, 2020; } \\
\text { Mallqui \& Fernandes, 2019) }\end{array}$ \\
\hline Crude oil price & https://tr.investing.com & $\begin{array}{l}\text { (Chen et al., 2021; Jang \& Lee, 2017; Jaquart et al., 2021; Li \& } \\
\text { Dai, 2020; Mallqui \& Fernandes, 2019) }\end{array}$ \\
\hline
\end{tabular}




\begin{tabular}{|c|c|c|}
\hline EUR/USD & https://tr.investing.com & $\begin{array}{l}\text { (Chen et al., 2021; Jaquart et al., 2021; Lamothe-Fernández et } \\
\text { al., 2020; Liu et al., 2020) }\end{array}$ \\
\hline CNY/USD & https://tr.investing.com & (Chen et al., 2021; Jang \& Lee, 2017; Jaquart et al., 2021) \\
\hline JPY/USD & https://tr.investing.com & $\begin{array}{l}\text { (Chen et al., 2021; Jang \& Lee, 2017; Jaquart et al., 2021; Liu et } \\
\text { al., 2020) }\end{array}$ \\
\hline \multicolumn{3}{|r|}{ Technical Variables } \\
\hline Hash rate & https://www.quandl.com & $\begin{array}{l}\text { (Albariqi \& Winarko, 2020; Chen et al., 2021; Dutta et al., 2020; } \\
\text { Jang \& Lee, 2017; Lamothe-Fernández et al., 2020; Liu et al., } \\
\text { 2020; Loh \& Ismail, 2020; Loh et al., 2020; Mallqui \& } \\
\text { Fernandes, 2019; Mudassir et al., 2020; Sin \& Wang, 2017; } \\
\text { Yavuz et al., 2020) }\end{array}$ \\
\hline $\begin{array}{l}\text { Mining } \\
\text { difficulty }\end{array}$ & https://www.quandl.com & $\begin{array}{l}\text { (Albariqi \& Winarko, 2020; Chen et al., 2021; Jang \& Lee, } \\
\text { 2017; Lamothe-Fernández et al., 2020; Li \& Wang, 2017; Liu et } \\
\text { al., 2020; Mudassir et al., 2020; Sin \& Wang, 2017; Yavuz et al., } \\
\text { 2020) }\end{array}$ \\
\hline $\begin{array}{l}\text { Miner's } \\
\text { revenue }\end{array}$ & https://www.quandl.com & $\begin{array}{l}\text { (Albariqi \& Winarko, 2020; Dutta et al., 2020; Jang \& Lee, } \\
\text { 2017; Lamothe-Fernández et al., 2020; Liu et al., 2020; Loh \& } \\
\text { Ismail, 2020; Loh et al., 2020; Sin \& Wang, 2017; Struga \& } \\
\text { Qirici, 2018; Yavuz et al., 2020) }\end{array}$ \\
\hline $\begin{array}{c}\text { Number of } \\
\text { Transactions }\end{array}$ & https://www.quandl.com & $\begin{array}{l}\text { (Albariqi \& Winarko, 2020; Chen et al., 2021; Dutta el al., 2020; } \\
\text { Jang \& Lee, 2017; Jaquart et al., 2021; Loh \& Ismail, 2020; Loh } \\
\text { et al., 2020; Mallqui \& Fernandes, 2019; Mudassir et al., 2020; } \\
\text { Sin \& Wang, 2017; Struga \& Qirici, 2018; Yavuz et al., 2020) }\end{array}$ \\
\hline $\begin{array}{l}\text { Average block } \\
\quad \text { size }\end{array}$ & https://www.quandl.com & $\begin{array}{l}\text { (Albariqi \& Winarko, 2020; Chen et al., 2021; Jang \& Lee, } \\
\text { 2017; Lamothe-Fernández et al., 2020; Loh \& Ismail, 2020; Loh } \\
\text { et al., 2020; Mudassir et al., 2020; Sin \& Wang, 2017; Struga \& } \\
\text { Qirici, 2018) }\end{array}$ \\
\hline $\begin{array}{l}\text { Bitcoins in } \\
\text { circulation }\end{array}$ & https://www.quandl.com & $\begin{array}{l}\text { (Albariqi \& Winarko, 2020; Dutta et al., 2020; Lamothe- } \\
\text { Fernández et al., 2020; Li \& Wang, 2017; Sin \& Wang, 2017; } \\
\text { Yavuz et al., 2020) }\end{array}$ \\
\hline $\begin{array}{l}\text { Cost per } \\
\text { transaction }\end{array}$ & https://www.quandl.com & $\begin{array}{l}\text { (Albariqi \& Winarko, 2020; Jang \& Lee, 2017; Lamothe- } \\
\text { Fernández et al., 2020; Loh \& Ismail, 2020; Loh et al., 2020; } \\
\text { Mallqui \& Fernandes, 2019; Sin \& Wang, 2017) }\end{array}$ \\
\hline $\begin{array}{l}\text { Total number } \\
\text { of unique } \\
\text { addresses }\end{array}$ & https://www.quandl.com & $\begin{array}{l}\text { (Albariqi \& Winarko, 2020; Jang \& Lee, 2017; Lamothe- } \\
\text { Fernández et al., 2020; Liu et al., 2020; Mudassir et al., 2020; } \\
\text { Sin \& Wang, 2017; Struga \& Qirici, 2018) }\end{array}$ \\
\hline
\end{tabular}

All input variables and an output variable stated in Table 1 are gathered for 01.05.2013 26.02.2021 periods from determined resources. Hence, the total number of considered data is stated as 1969. After that, all datasets are normalized for eliminating unit differences of variables. The normalization procedure is executed with the help of the formula below:

$$
x^{\prime}=\frac{x_{i}-x_{\min }}{x_{\max }-x_{\min }}, \quad x^{\prime} \text { is the normalized value of } x_{i}
$$

Afterward, the dataset is divided into two subsets for training and testing. In plenty of studies, datasets usually split like 50:50, 60:40, 70:30, 80:20, or 90:10 based on convenience. Since there are many observations in the dataset, \%90 training sample is seemed sufficient and 90:10 ratios are chosen. Hence, $90 \%$ of the dataset (1774) for training and $10 \%$ of the dataset (195) for testing are allocated. It should also be emphasized that the test dataset is from a 
future period that is not known at the current moment. Therefore, it creates a robust test for understanding the forecasting capability of the ANFIS model.

\section{FINDINGS}

In this study, Bitcoin cryptocurrency's closing prices are forecasted with ANFIS GUI which is a function of Fuzzy Logic Toolbox in the MATLAB R2015a program. Since the ANFIS model outperforms with less input is a well-known fact (Jang, 1993), the number of inputs utilized is aimed to limit up to four (4) inputs at the highest. By using the "exhsrch" command, the most influential inputs can be selected easily in MATLAB Program. In line with program recommendations, two (2) economical (crude oil price and S\&P500 index) and two (2) technical variables (hash rate and miners' revenue) were considered as the most influential variables on output. After this stage, considering new recommended input and output variables, the dataset was arranged once again. In line with the newly generated dataset, samples of training and testing datasets are demonstrated in Table 2 and Table 3, respectively.

Table 2. Training Data Sample (Last 10)

\begin{tabular}{|c|c|c|c|c|}
\hline $\begin{array}{c}\text { Crude } \\
\text { Oil } \\
\text { Price }\end{array}$ & $\begin{array}{c}\text { S\&P500 } \\
\text { Index }\end{array}$ & $\begin{array}{c}\text { Hash } \\
\text { Rate }\end{array}$ & $\begin{array}{c}\text { Miners' } \\
\text { Revenue }\end{array}$ & $\begin{array}{l}\text { Bitcoin } \\
\text { Price }\end{array}$ \\
\hline 0.4526 & 0.4940 & 0.5041 & 0.1082 & 0.1457 \\
\hline 0.4400 & 0.4897 & 0.4597 & 0.0992 & 0.1530 \\
\hline 0.4247 & 0.4773 & 0.4799 & 0.0939 & 0.1454 \\
\hline 0.4280 & 0.4965 & 0.5888 & 0.1080 & 0.1378 \\
\hline 0.4169 & 0.5195 & 0.6332 & 0.2109 & 0.1341 \\
\hline 0.4210 & 0.5193 & 0.5525 & 0.2247 & 0.1534 \\
\hline 0.4129 & 0.5007 & 0.5928 & 0.2244 & 0.1562 \\
\hline 0.4159 & 0.4882 & 0.6211 & 0.2540 & 0.1431 \\
\hline 0.4197 & 0.4959 & 0.6362 & 0.2249 & 0.1407 \\
\hline 0.3916 & 0.4860 & 0.6314 & 0.2201 & 0.1387 \\
\hline
\end{tabular}

Table 3. Testing Data Sample (Last 10)

\begin{tabular}{|c|c|c|c|c|}
\hline $\begin{array}{c}\text { Crude } \\
\text { Oil } \\
\text { Price }\end{array}$ & $\begin{array}{c}\text { S\&P500 } \\
\text { Index }\end{array}$ & $\begin{array}{c}\text { Hash } \\
\text { Rate }\end{array}$ & $\begin{array}{l}\text { Miners' } \\
\text { Revenue }\end{array}$ & $\begin{array}{l}\text { Bitcoin } \\
\text { Price }\end{array}$ \\
\hline 0.6691 & 0.8567 & 0.7562 & 0.5895 & 0.7291 \\
\hline 0.6828 & 0.8637 & 0.8486 & 0.7197 & 0.7383 \\
\hline 0.6807 & 0.9005 & 0.8650 & 0.7442 & 0.7819 \\
\hline 0.6702 & 0.8836 & 0.6909 & 0.6032 & 0.7695 \\
\hline 0.6690 & 0.8817 & 0.7235 & 0.6585 & 0.8514 \\
\hline 0.6538 & 0.8933 & 0.8220 & 0.7379 & 0.8797 \\
\hline 0.6625 & 0.8961 & 0.7353 & 0.6682 & 0.8116 \\
\hline 0.6471 & 0.8970 & 0.6924 & 0.5893 & 0.7550 \\
\hline 0.6500 & 0.8945 & 0.7675 & 0.6150 & 0.7053 \\
\hline 0.6479 & 0.8950 & 0.7675 & 0.6426 & 0.7317 \\
\hline
\end{tabular}

All data were loaded to the working space. The graphics below were produced in Figure 3 and Figure 4 relatedly with that.

Figure 3. All Training Data Display

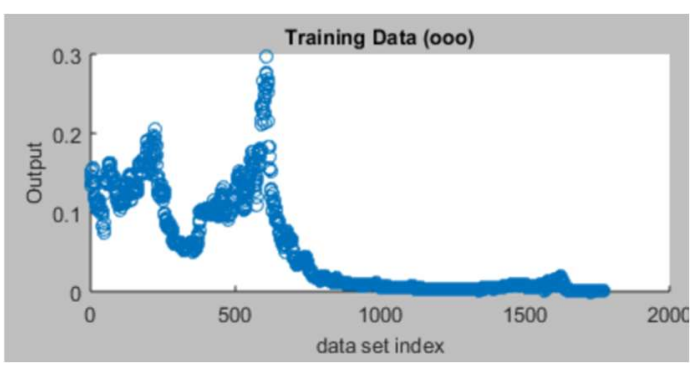

Figure 4. All Testing Data Display

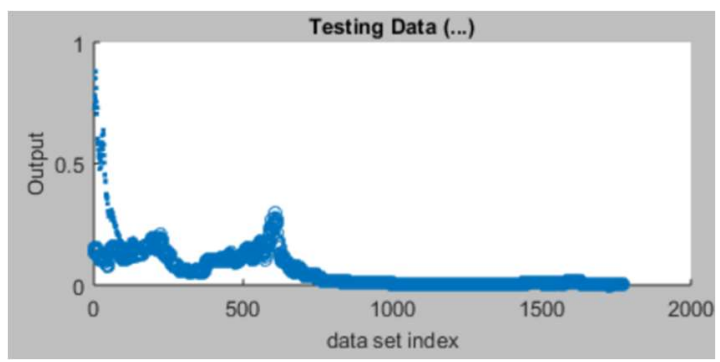


The "Grid Partition" method was chosen to create the fuzzy inference system in the training data set. After that, to obtain optimal epoch number, 5-10-20-30-40 iterations were tried, respectively. 20 iterations were accepted because the results did not change substantially. Hence, "optimization method" and "epoch number" were determined as "hybrid" and "20" respectively. Additively, the optimum number and type of both input and output membership functions' were needed to be determined. So, the features that gave the least error were preferred for our model. In this study, it was found that the "4" membership function for each input, the "Generalized bell-shaped membership function (gbellMF)" membership function input type, and the "linear" output membership type were found to be the most suitable solution.

2 membership functions are defined for 4 input variables. In order to express ANFIS rule bases verbally, the first membership function was named as "low" and the second membership function as "high". This classification process shows which value belongs to which function at which rate. After the training, the graphs of the membership functions of input variables are given in Figure 5, Figure 6, Figure 7, and Figure 8. After the training process, it is seen that membership functions try to adapt to the system in places where the error rate is high.

Figure 5. Membership Degrees Belonging to the "Crude Oil Price" Variable

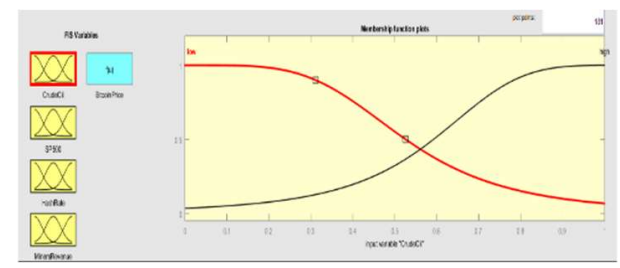

Figure 7. Membership Degrees Belonging to the "Hash Rate" Variable

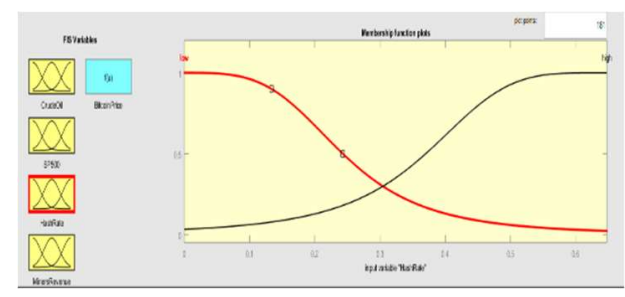

Figure 6. Membership Degrees Belonging to the "S\&P500 Index" Variable

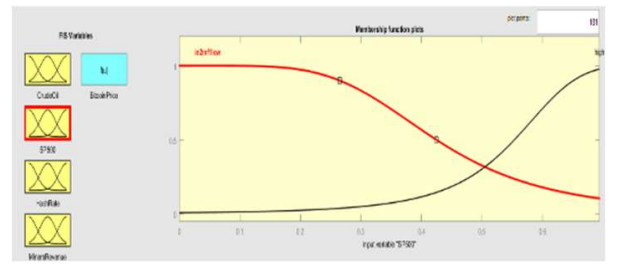

Figure 8. Membership Degrees Belonging to the "Miners' Revenue" Variable

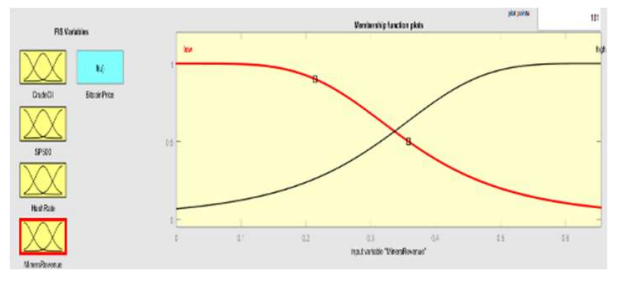

Figure 9 shows the ANFIS structure of the Bitcoin price prediction model. While black nodes imply input variables, first white nodes indicate input membership functions, and the 
following blue nodes demonstrate ANFIS rules. Related rules produce outputs' membership functions (second white nodes) and all these lead to forecast output variables.

Figure 9. ANFIS Model Structure

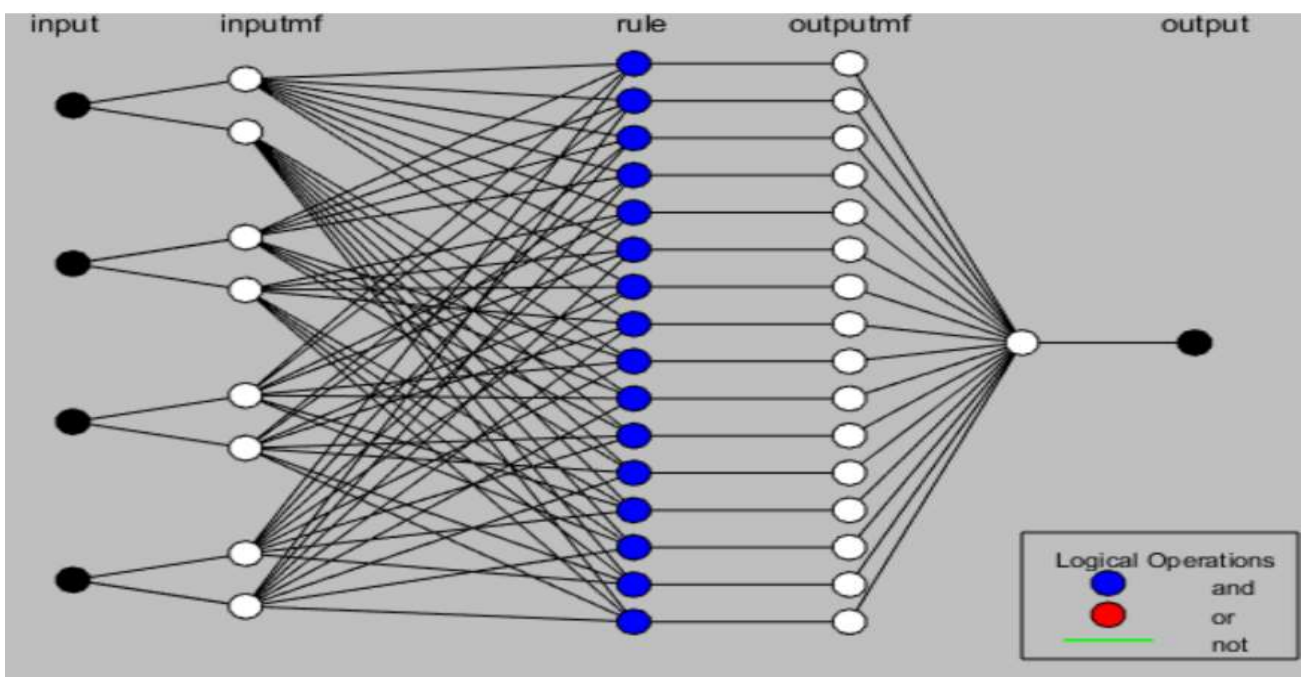

In Figure 9, the ANFIS model structure can be detected. As easily seen on the graphic, a total $(24=16)$ rules were produced by 4 inputs via 2 membership functions. In other words, the fuzzy network model determined 16 rules that would best realize learning and they produced a single output value. This model is saved as final the ANFIS model.

In this stage, the input-output values in the training data set were introduced to the ANFIS model. ANFIS model is expected to create an ANFIS output by learning the structure of the relationships between inputs and outputs. The ANFIS model is expected to have little error at the end of the training. The error rate is calculated with the help of the formula (7) below:

Root Mean Square Error $(\mathrm{RMSE})=\sqrt{\frac{\sum_{\mathrm{t}=1}^{\mathrm{N}} \mathrm{e}_{\mathrm{t}}^{2}}{\mathrm{~N}}}$

RMSE measure intends to determine differences between forecasts provided by the ANFIS model and actual outcomes. Figure 10 below shows the graph of the relationship between "Real Data" and "ANFIS training model output". 
Figure 10. Relationship Between "Real Data” and "ANFIS Training Model Output"

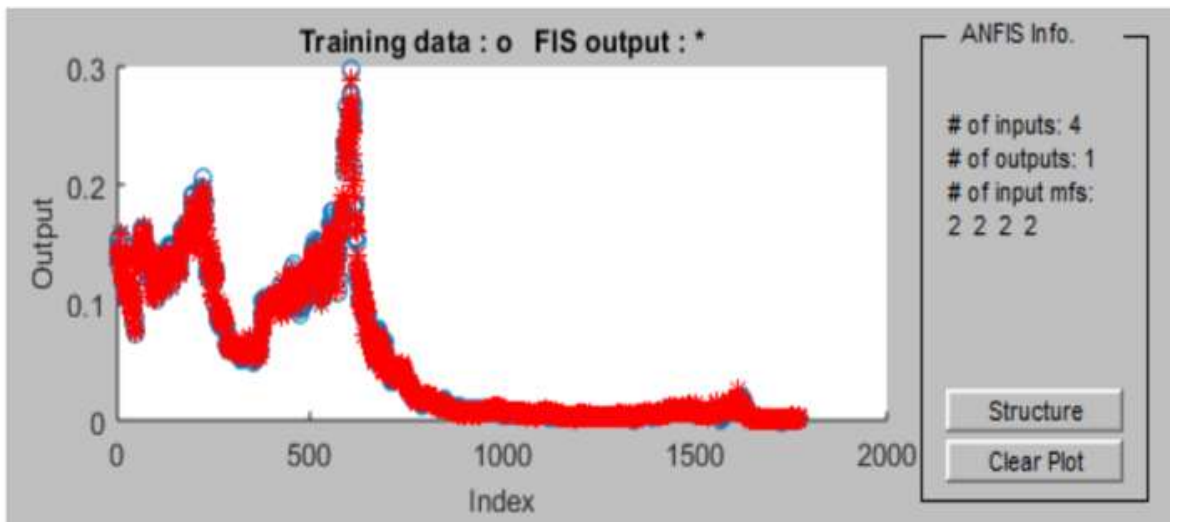

The training error value is found at 0,0053732 (Root Mean Square Error-RMSE value). The overlap of the values in the training data set and the predicted values of the ANFIS model can be clearly seen in Figure 10. While the "blue circles" show the actual values of the training data, the "red stars" represent the predicted values of the ANFIS model. The superposition of the two symbols shows how effectively the model learned.

Figure 11. Relationship Between "Real Data" and "ANFIS Testing Model Output"

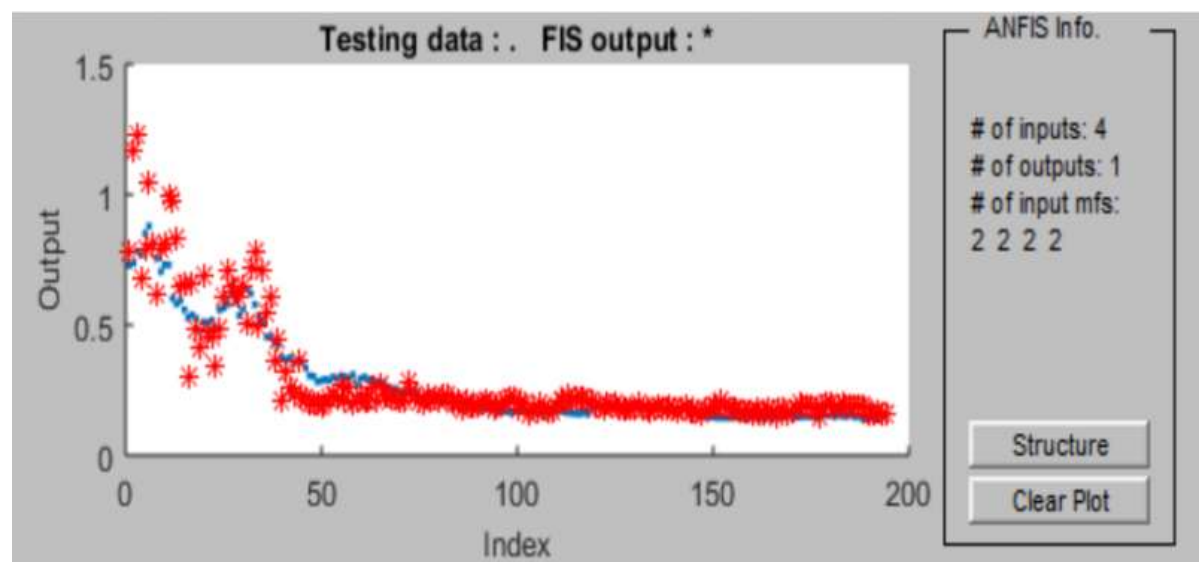

After obtaining the forecasts for the training model, the forecasting process is realized for the ANFIS test dataset. In this section, forecasts are made for the data that have not been shown to the ANFIS model before. Hence, the ANFIS model is being expected to make an accurate forecast for future values that are not known at the current moment. In Figure 11, "blue circles" show the actual values of the testing data and the "red stars" represent the forecasted values of the ANFIS model. According to the graph, the values of training data and ANFIS predicted values are seemed quite close to each other. Moreover, the testing error rate is found at 0,083966 (Root Mean Square Error-RMSE value). In other words, the values of the testing data are estimated with very little error (with $\% 8$ error rate). The superposition of the two symbols indicates the robustness and effectiveness of the forecasting model. So it can be 
concluded that the forecasting model belongs to this study makes very accurate forecasts for the future. ANFIS parameters can be summed up in Table 4 below:

Table 4. Parameter Configuration ANFIS

\begin{tabular}{lc}
\hline Specifications & ANFIS \\
\hline Inference mechanism type & Sugeno \\
\hline Number of inputs & 4 \\
\hline 1st input & crude oil price price \\
\hline 2nd input & S\&P500 index \\
\hline 3rd input & hash rate \\
\hline 4rd input & miners' revenue \\
\hline Outputs & 1 \\
\hline Output & Bitcoin Price \\
\hline And method & prod \\
\hline Or method & probor \\
\hline Imp. Method & prod \\
\hline Agg. Method & sum \\
\hline Defuzz. Method & wtaver \\
\hline Number of Rules & 16 \\
\hline Type of MFs & gbellMF \\
\hline The number for training data & 1774 \\
\hline The number for evaluation data & 195 \\
\hline
\end{tabular}

The rules generated by ANFIS are shown in Figure 11. There are the numbers of the rules on the left side of the figure. In the first four columns, input variables are stated and on the last column, the output value that the ANFIS system served is demonstrated. For example, according to one of the results of Figure 12, when the crude oil price is 0,500, S\&P500 index is 0,347 , hash rate is 0,324 , and miners' revenue is 0,327 ; Bitcoin price is found 0,343 . Red lines on the editor can move from left and to right. Hence, the values change accordingly. But identifying all values by this method seems like a harsh mission. In these situations, the command "evalfis" is used to display the outputs of the test data in a list. So, with the "evalfis" command all the forecasted output values can be detected easily.

Figure 12. Rule Base Editor

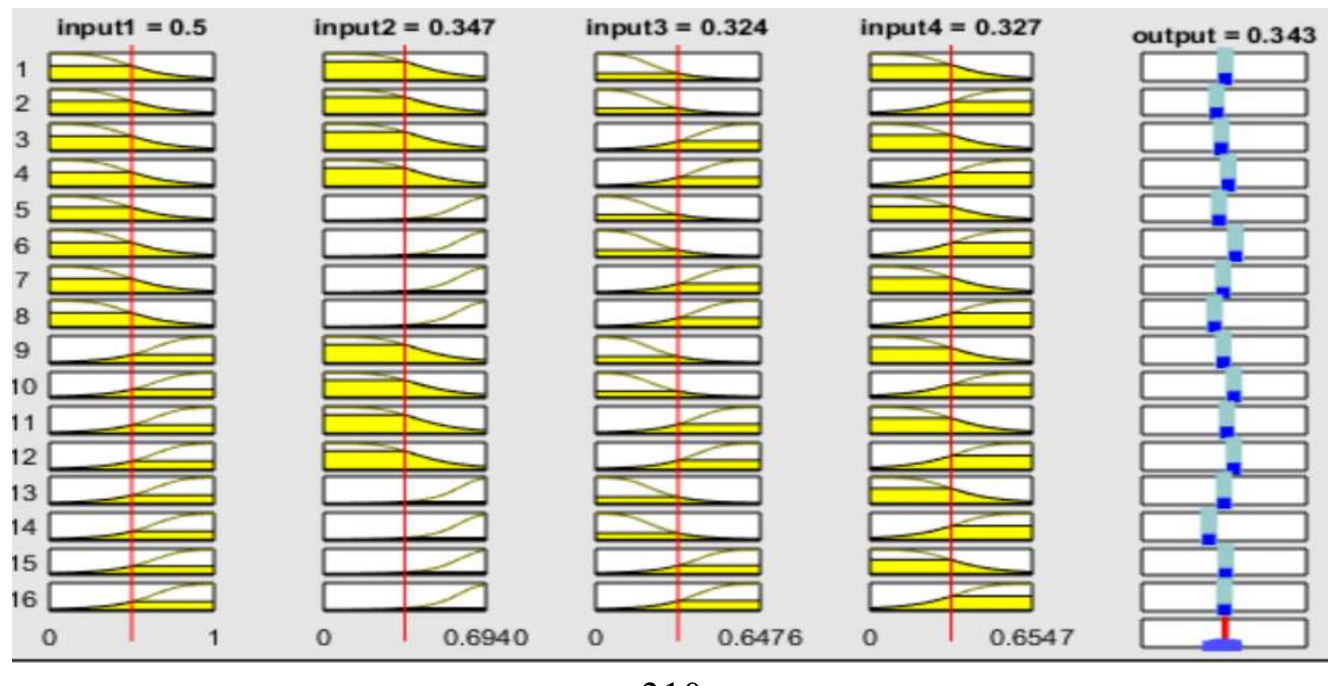


Normalized ANFIS forecasts for the last ten (10) test data (for 9.02.2021-26.02.2021 period) resulting from this command can be stated as follows:

Ans $=0.7765 ; 1.1696 ; 1.2293 ; 0.6741 ; 0.7935 ; 1.0456 ; 0.8095 ; 0.6147 ; 0.7920 ; 0.7920$

Finally, it can be expressed that with the help of selected inputs as "crude oil price", "S\&P500 index", "hash rate" and "miners' revenue" values, accurate future forecasting can easily occur.

\section{CONCLUSIONS}

Rapid and trustworthy financial transaction systems are in high demand as a result of technological innovations, the internet era, and Industrial 4.0. Cryptocurrencies (digital currencies) have recently gained interest in this regard. The projected market value of the cryptocurrency has surpassed the hundreds of billions of dollars level. With a market value of $\$ 659$ billion, Bitcoin is the most popular cryptocurrency today (coinmarketcap.com). Government shutdowns and policies made investors worried about the global economy during the Covid-19 outbreak, leading them to invest in the Bitcoin market (Edward, 2021).

Since cryptocurrencies have recently gained this much popularity nowadays, forecasting efforts of their pricing have newly become a charming issue for both researchers and investors. Although many studies attempted to forecast the Bitcoin future prices, there are fewer studies that are conducted with the help of neural network methods. This research aims to use one of the most well-known artificial intelligence models, ANFIS, to anticipate the future Bitcoin values from May 1, 2013, through February 26, 2021.

The fluctuation of Bitcoin prices is well recognized to be influenced by a variety of factors. We conducted a comprehensive assessment of the Bitcoin forecasting literature and discovered a variety of related factors. Afterward, we divided all variables into economic and technical categories. Economic variables were obtained as "S\&P 500 index", "Dow Jones index", "gold price", "crude oil price" and "EUR/USD", "CNY/USD" and "JPY/USD" exchange rates. Bitcoins" technical variables were indicated as "hash rate", "mining difficulty", "miner's revenue", "number of transactions", "average block size", "Bitcoins in circulation", "cost per transaction" and "total number of unique addresses".

Computational intelligence models generally outperform with fewer input variables. Therefore, we needed to keep inputs to a minimum level. With the help of the ANFIS model, we reduced the input number. Finally, input variables are determined as "crude oil price", "S\&P500 index", "hash rate" and "miners' revenue". After this stage, we divided the data into 
two parts as training and testing. We provided our input and output values to the ANFIS model during the training phase and allowed it to understand the design between them. Ultimately, the ANFIS model had a very low error rate (0.005), indicating that it had learned the relationship extremely effectively. As a result, the ANFIS model appeared to be capable of making future predictions. Then, we moved on to the training phase, where we discovered that the ANFIS model produced forecasts that were extremely close to the actual future data. In other words, while forecasting, the ANFIS model produced a remarkably low error rate $(0,084)$. Consequently, the ANFIS model produced accurate and consistent forecasting results that were in line with the actual data.

In this context, when researchers enter their expected "crude oil price", "S\&P500 index", "hash rate" and "miners' revenue" values into the ANFIS model, they may acquire consistent forecast values with reality. All these findings clearly indicate the success of the ANFIS forecasting model. Therefore, investors who want to gain some revenue by forecasting future Bitcoin prices are suggested to use the ANFIS model as a forecasting tool. In future studies, other neural fuzzy forecasting models might be added to the analysis to compare ANFIS forecasting results.

\section{REFERENCES}

Adjei, F. (2019). Determinants of bitcoin expected returns. Journal of finance and economics, $7(1), 42-47$.

Aggarwal, D., Chandrasekaran, S., \& Annamalai, B. (2020). A complete empirical ensemble mode decomposition and support vector machine-based approach to predict bitcoin prices. Journal of behavioral and experimental finance, 27, 100335.

Akyildirim, E., Goncu, A., \& Sensoy, A. (2021). Prediction of cryptocurrency returns using machine learning. Annals of operations research, 297(1), 3-36.

Albariqi, R., \& Winarko, E. (2020, February). Prediction of bitcoin price change using neural networks [Conference presentation]. International Conference on Smart Technology and Applications (ICoSTA), 1-4.

Altan, A., Karasu, S., \& Bekiros, S. (2019). Digital currency forecasting with chaotic metaheuristic bio-inspired signal processing techniques. Chaos, solitons \& fractals, 126, 325-336.

Atsalakis, G. S., Atsalakis, I. G., Pasiouras, F., \& Zopounidis, C. (2019). Bitcoin price forecasting with neuro-fuzzy techniques. European journal of operational research, 276(2), 770-780.

Bayramoğlu, T., Pabuççu, H., \& Çelebi Boz, F. (2017). Türkiye için anfıs modeli ile birincil enerji talep tahmini. Ege akademik bakış, 17(3), 431-446. 
Chen, T. H., Chen, M. Y., \& Du, G. T. (2021). The determinants of bitcoin's price: Utilization of GARCH and machine learning approaches. Computational Economics, 57(1), 267280 .

Chen, W., Xu, H., Jia, L., \& Gao, Y. (2021). Machine learning model for bitcoin exchange rate prediction using economic and technology determinants. International journal of forecasting, 37(1), 28-43. https://doi.org/10.1016/j.ijforecast.2020.02.008

Ciaian, P., Rajcaniova, M., \& Kancs, D. A. (2016). The economics of bitcoin price formation. Applied economics, 48(19), 1799-1815.

Dutta, A., Kumar, S., \& Basu, M. (2020). A gated recurrent unit approach to bitcoin price prediction. Journal of risk and financial management, 13(2), 1-16. https://doi.org/10.3390/jrfm13020023.

Edwards, J. (2021). Bitcoin's Price History. In Investopedia. https://www.investopedia.com/articles/forex/121815/bitcoins-price-history.asp (Retrieved 12.06.2021).

Fortune Business Insight (2020), https://www.fortunebusinessinsights.com/industryreports/cryptocurrency-market-100149 (Retrieved 31.05.2021).

Georgoula, I., Pournarakis, D., Bilanakos, C., Sotiropoulos, D., \& Giaglis, G. M., Using Time-Series and Sentiment Analysis to Detect the Determinants of Bitcoin Prices (May 17, 2015). Available at SSRN: https://ssrn.com/abstract=2607167 (Retrieved 19.05.2021)

Guizani, S., \& Nafti, I. K. (2019). The determinants of bitcoin price volatility: an investigation with ardl model. Procedia computer science, 164, 233-238.

Jang, J. R. (1993). Anfis : adaptive-network-based fuzzy inference system. Ieee transactions on systems, man, and cybernetics, 23(3), 665-685.

Jang, H., \& Lee, J. (2017). An empirical study on modeling and prediction of bitcoin prices with bayesian neural networks based on blockchain information. Ieee access, 6, 54275437. https://doi.org/10.1109/ACCESS.2017.2779181

Jaquart, P., Dann, D., \& Weinhardt, C. (2021). Short-term bitcoin market prediction via machine learning. The journal of finance and data science, 7, 45-66. https://doi.org/10.1016/j.jfds.2021.03.001

Jay, P., Kalariya, V., Parmar, P., Tanwar, S., Kumar, N., \& Alazab, M. (2020). Stochastic neural networks for cryptocurrency price prediction. Ieee access, 8, 82804-82818.

Ji, S., Kim, J., \& Im, H. (2019). A comparative study of bitcoin price prediction using deep learning. Mathematics, 7(10), 898.

Karasu, S., Altan, A., Saraç, Z., \& Hacioğlu, R. (2018). Prediction of Bitcoin prices with machine learning methods using time series data [Conference Presentation]. 26th signal processing and communications applications conference (SIU), 1-4.

Kristjanpoller, W., \& Minutolo, M. C. (2018). A hybrid volatility forecasting framework 
integrating garch, artificial neural network, technical analysis and principal components analysis. Expert systems with applications, 109, 1-11.

Kristoufek, L. (2013). Bitcoin meets google trends and wikipedia: quantifying the relationship between phenomena of the internet era. Scientific reports, 3(1), 1-7.

Kristoufek, L. (2015). What are the main drivers of the Bitcoin price? Evidence from wavelet coherence analysis. PloS one, 10(4), e0123923.

Lahmiri, S., \& Bekiros, S. (2019). Cryptocurrency forecasting with deep learning chaotic neural networks. Chaos, solitons \& fractals, 118, 35-40.

Lamothe-Fernández, P., Alaminos, D., Lamothe-López, P., \& Fernández-Gámez, M. A. (2020). Deep learning methods for modeling bitcoin price prosper. Mathematics, $8(8)$, 1-13. https://doi.org/10.3390/MATH8081245

Li, X., \& Wang, C. A. (2017). The technology and economic determinants of cryptocurrency exchange rates: the case of bitcoin. Decision support systems, 95, 49-60. https://doi.org/10.1016/j.dss.2016.12.001

Li, Y., \& Dai, W. (2020). Bitcoin price forecasting method based on cnn-lstm hybrid neural network model. The journal of engineering, 2020(13), 344-347. https://doi.org/10.1049/joe.2019.1203

Liu, M., Li, G., Li, J., Zhu, X., \& Yao, Y. (2021). Forecasting the price of bitcoin using deep learning. Finance research letters, 40, 101755.

Loh, E. C., \& Ismail, S. (2020). Emerging trend of transaction and investment: bitcoin price prediction using machine learning. International journal of advanced trends in computer science and engineering, 9(1.4), 100-104. https://doi.org/10.30534/ijatcse/2020/1591.42020

Loh, E. C., Ismail, S., Khamis, A., \& Mustapha, A. (2020). Comparison of feedforward neural network with different training algorithms for bitcoin price forecasting. Asm science journal, 13, 1-7. https://doi.org/10.32802/asmscj.2020.sm26(1.5)

McNally, S., Roche, J., \& Caton, S. (2018). Predicting the price of bitcoin using machine learning [Conference Presentation]. 26th euromicro international conference on parallel, distributed and network-based processing (PDP), 339-343.

Malik, S. (2020). Drivers of bitcoin prices: an empirical analysis of india. Journal of critical reviews, 7(14), 1252-1258.

Mallqui, D. C. A., \& Fernandes, R. A. S. (2019). Predicting the direction, maximum, minimum and closing prices of daily bitcoin exchange rate using machine learning techniques. Applied soft computing journal, 75, 596-606. https://doi.org/10.1016/j.asoc.2018.11.038

Mudassir, M., Bennbaia, S., Unal, D., \& Hammoudeh, M. (2020). Time-series forecasting of bitcoin prices using high-dimensional features: a machine learning approach. Neural computing and applications, 6, 1-15. https://doi.org/10.1007/s00521-020-05129-6 
Nakamoto, S. (2009). Bitcoin: Peer-to-Peer Electronic Cash System. https://nakamotoinstitute.org/bitcoin/, (Retrieved 01.05.2021).

Nakano, M., Takahashi, A., \& Takahashi, S. (2018). Bitcoin technical trading with artificial neural network. Physica a: statistical mechanics and its applications, 510, 587-609.

Panagiotidis, T., Stengos, T., \& Vravosinos, O. (2018). Pn the determinants of bitcoin returns: a lasso approach. Finance research letters, 27, 235-240.

Patel, M. M., Tanwar, S., Gupta, R., \& Kumar, N. (2020). A deep learning-based cryptocurrency price prediction scheme for financial institutions. Journal of information security and applications, 55, 102583.

Pintelas, E., Livieris, I. E., Stavroyiannis, S., Kotsilieris, T., \& Pintelas, P. (2020). Investigating the problem of cryptocurrency price prediction: a deep learning approach [Conference Presentation]. IFIP International conference on artificial intelligence applications and innovations, 99-110.

Poongodi, M., Sharma, A., Vijayakumar, V., Bhardwaj, V., Sharma, A. P., Iqbal, R., \& Kumar, R. (2020). Prediction of the price of ethereum blockchain cryptocurrency in an industrial finance system. Computers \& electrical engineering, 81, 106527.

Poyser, O. (2019). Exploring the dynamics of bitcoin's price: a bayesian structural time series approach. Eurasian economic review, 9(1), 29-60.

Sin, E., \& Wang, L. (2017). Bitcoin price prediction using ensembles of neural networks [Conference Presentation]. 13th international conference on natural computation, fuzzy systems and knowledge discovery, 666-671.

Shen, D., Urquhart, A., \& Wang, P. (2019). Does twitter predict bitcoin?. Economics letters, 174, 118-122.

Struga, K., \& Qirici, O. (2018). Bitcoin price prediction with neural networks. Ceur workshop proceedings, 2280, 41-49.

Sovbetov, Y. (2018). Factors influencing cryptocurrency prices: evidence from bitcoin, ethereum, dash, litcoin, and monero. Journal of economics and financial analysis, 2(2), $1-27$.

Urfalığlu, F., \& Tanrıverdi, İ. (2018). Anfis ve regresyon analizi ile enflasyon tahmini ve karş1laştırması. Social sciences research journal, 7(3), 120-141.

Yavuz, U., Özen, Ü., Taş, K., \& Çağlar, B. (2020). Yapay sinir ağları ile blockchain verilerine dayalı bitcoin fiyat tahmini. Journal of information systems and management research, 2(1), 1-9.

Yücel, A., \& Güneri, A. F. (2010). Application of adaptive neuro fuzzy inference system to supplier selection problem. Journal of engineering and natural sciences, 28(212), 224234.

www.coinmarketcap.com (Accessed: 12.06.2021 